Revista Destaques Acadêmicos, Lajeado, v. 10, n. 2, 2018. ISSN 2176-3070

DOI: http://dx.doi.org/10.22410/issn.2176-3070.v10i2a2018.1864

http://www.univates.br/revistas

\title{
QUANDO MIGRAR É NECESSÁRIO: AÇORIANOS POVOAM O CONTINENTE DE RIO GRANDE DE SÃO PEDRO (MEADOS DO SÉCULO XVIII)
}

\author{
Cibele Caroline da Rosa ${ }^{1}$, Luís Fernando da Silva Laroque ${ }^{2}$
}

Resumo: O artigo pretende-se como uma compilação de estudos acerca da migração de açorianos para o Rio Grande do Sul durante o século XVIII, tendo como foco principal a Freguesia de São José de Taquari, a qual deu origem ao município de mesmo nome. Objetiva-se discutir sobre a migração das gentes das Ilhas para o Continente de Rio Grande de São Pedro a partir de duas etapas. A primeira se concentra nos motivos discutidos pela historiografia para a saída dos açorianos do Arquipélago do Açores e a segunda parte aborda a chegada dos migrantes e a disposição dos mesmos nas terras sulinas, dentre elas a Freguesia de Taquari, criada em 1764. O uso de fontes é realizado de maneira qualitativa e colabora na análise das referências bibliográficas.

Palavras-chave: Migração açoriana. Freguesia de Taquari. Historiografia.

\section{INTRODUÇÃO}

Em meados do século XVIII, homens e mulheres, moradores do conjunto de ilhas que forma o Arquipélago dos Açores, deslocaram-se para o povoamento das terras meridionais da América Lusa, alvo de conflitos com a Coroa Espanhola. Enquanto os portugueses buscavam expandir suas terras para além do Tratado de Tordesilhas, assinado antes da chegada às terras americanas, os espanhóis buscavam resguardar as terras que lhes foram

1 Mestranda em História/UNISINOS. Bolsista CNPq. Graduada em História/UNIVATES. cibelecaroldarosa@gmail.com.

2 Doutor em História. Professor e pesquisador do Programa de Pós-Graduação em Ambiente e Desenvolvimento e do Curso de Graduação em História da UNIVATES. Iflaroque@univates.br. 
concedidas pelo referido Tratado ${ }^{3}$ É neste ambiente de litígio que casais das ilhas são convocados a povoar o Continente de Rio Grande de São Pedro.

Com a promessa fundamental de manter o idioma português na fronteira com o espanhol (CARVALHO, 2002; MENEZES, 2014), a migração dos súditos açorianos se configurou como uma prática importante dentro das pretensões portuguesas para a manutenção do território lusitano na fronteira sul. Além disso, a migração dos açorianos também imporia um maior contingente português em terras que, até então, eram espanholas.

Este artigo é resultado das discussões realizadas para a elaboração do Trabalho de Conclusão de Curso em História, da Universidade do Vale do Taquari - UNIVATES. Pretende-se abordar, a partir da revisão bibliográfica de historiadores que se debruçaram a estudar a migração dos açorianos para o Brasil Meridional durante o século XVIII, as condicionantes da saída dos migrantes e como se deu a disposição dos mesmos. Esses que se deslocaram na esperança e tentativa de melhorar suas condições de vida do outro lado do Atlântico. Além da revisão bibliográfica, o uso das fontes de caráter qualitativo colabora no entendimento de tal processo histórico.

\section{CONDICIONANTES DA MIGRAÇÃO}

Portugal se encontra administrativa e geograficamente dividido entre a parte Continental e a parte Insular, sendo que esta última é composta pelas Ilhas da Madeira e dos Açores. Colonizados em meados do século XV por portugueses e flamengos, as nove ilhas que compõe o arquipélago são domínio português desde 1432, como resultado do processo de navegações (TORRES, 2004). De acordo com Cleidirose Silva (2009), o nome do arquipélago provém de uma ave de rapina denominada "açor". Ao todo, são nove ilhas divididas em três conjuntos: Santa Maria e São Miguel; Terceira, São Jorge, Graciosa, Pico e Faial; Flores e Corvo (SILVA, 2009).

No século XVIII, as condições no Arquipélago dos Açores favoreciam a migração de súditos da Coroa Portuguesa para as terras americanas ${ }^{4}$. José Damião Rodrigues (2016) destaca que o comércio entre os portos açorianos e os brasileiros se dava tanto de maneira legal quanto pelo contrabando,

3 Há de se considerar, que na análise, são levados em conta os projetos de expansão dos impérios ibéricos, os quais desconsideravam a presença indígena em muitos lugares, como no caso da região que hoje é conhecida como Vale do Taquari. Como destaca Christillino (2004), havia o entendimento, por parte da Coroa Portuguesa, de um hiato demográfico na região, fato que deve ser relativizado se pensar a presença de grupos indígenas na região.

4 Não se pode desconsiderar que a migração sempre foi uma constante na vida dos ilhéus, assim como da população portuguesa. Antes mesmo do Edital de 1747, já havia levas de moradores do conjunto de ilhas que se deslocavam para o Brasil. Isso também ocorreu após o Edital, tornando-se uma prática comum para os açorianos (GRAEBIN, 2004; HAMEISTER, 2006). 
movimentando a economia local dos Açores. A partir do século XVIII, com a abertura da navegação a particulares, os movimentos foram se intensificando. Assim, Feliciano Velho Oldenberg recebeu, em 1740, a autorização de transportar tabaco para o Brasil desde que, em cada viagem, transportasse um casal de novos povoadores.

A entrada de povoadores açorianos no Brasil também foi demonstrada por Maria Luiza Bertulini Queiroz (1985). De acordo com a referida autora, já no século XVII, há registros de entradas dos açorianos no Maranhão e ainda no Pará ${ }^{5}$, demonstrando uma comunicação entre os moradores dos Açores e as terras americanas pertencentes à Coroa Lusa. Nesta exposição, procurase destacar três fatores centrais, os quais são considerados de fundamental relevância para compreender o processo de saída dos açorianos do arquipélago: os ambientais, a miséria dos ilhéus e o sistema de heranças predominante em Portugal.

De acordo com Cleusa Maria Graebin (2004), as ilhas passaram por mais de trinta cataclismos distribuídos entre 1614 e 1755. Abalos sísmicos e vulcões fizeram parte da história dos indivíduos nascidos e moradores do arquipélago, sendo que entre os anos de 1713 e 1730, as Ilhas de São Miguel, Pico, Terceira e Faial passaram por diversos abalos. Neste sentido, as condições climáticas naturais, impreterivelmente, abalaram algumas das condições socioeconômicas dos moradores. Além disso, "terror e incerteza seriam as palavras adequadas para caracterizar as condições em que viviam os habitantes do Arquipélago dos Açores" (GRAEBIN, 2004, p. 83).

Ainda de acordo com Graebin (2004), após uma série de cataclismos terem acontecido no arquipélago durante a década de 1720, a ilha do Faial foi a única que não havia sido afetada. Os moradores da localidade de Horta passaram, então, a realizar, anualmente, uma festa em honra a Santo Cristo, evento religioso que acontece até os dias atuais. As orações faziam parte do dia a dia dos moradores do arquipélago e, nos momentos de dificuldade, a fé, numa solução divina, colaborava na manutenção das esperanças destes habitantes.

Henrique Wiedersphan, na obra "A colonização açoriana no Rio Grande do Sul" (1979), referindo-se a uma erupção vulcânica na Ilha de Faial em 1746 , a considera como uma das piores que atormentaram as ilhas durante a primeira metade do século XVIII, pois as freguesias da referida ilha ficaram completamente destruídas. Humanos, animais e casas foram levados pelas lavas até o mar, abalando profundamente a vida dos moradores. Além disso, as pessoas que se salvaram sofreram pela falta de alimentos, pois as lavouras também haviam sido destruídas. Nesse caso, como destacam Wiedersphan

5 Contudo, como ressalta a autora, tais migrações anteriores ao Edital de 1747 eram caracterizadas pela forte presença masculina - sem desconsiderar a feminina -, "de caráter individual, 'quase todas de homens solteiros', açorianos, madeirenses e caboverdeanos" (QUEIROZ, 1985, p. 124). 
(1979) e Graebin (2004), a saída das ilhas e a vinda para as terras americanas foram uma tentativa de melhorar as condições de vida daqueles moradores.

Outro motivo que a historiografia aponta como condicionante para a saída de moradores das ilhas é a miséria abundante no arquipélago. Os ilhéus sonhavam com condições melhores de trabalho e vida. Fabio Kühn (2014) destaca que, antes do descobrimento do ouro no centro da colônia portuguesa, havia a forte intenção de migrar para o sul. Nesse sentido, os ilhéus ainda sonhavam com o seu Eldorado na tentativa de melhor viver e gerir suas vidas (GRAEBIN, 2006).

De acordo com Cleusa Graebin (2004), a imagem das terras brasileiras recorrente nas ilhas era povoada da possibilidade de enriquecimento rápido e fácil. Elas eram divulgadas, principalmente, a partir de tripulantes que desembarcavam nas ilhas. Neste sentido, as imagens de uma possível prosperidade e ainda as más condições de vida que os habitantes do arquipélago enfrentavam colaboraram para pedidos de transferência de gentes das ilhas para o meridional brasileiro. Esta miséria era advinda, principalmente, dos cataclismos referidos.

O trigo era o principal cereal colhido nos Açores. Durante os anos de 1742 a 1745, nenhum alqueire do cereal havia sido produzido, o que aumentava muito a miséria dos ilhéus. Era o trigo a principal fonte de sustento econômico da população açorita. Conforme Graebin (2004, p. 87), “o trigo cultivado nos Açores, além de ser dos componentes fundamentais na alimentação dos ilhéus, também era negociado nas praças de Lisboa, Marrocos e Brasil, sendo importante ao equilíbrio econômico das ilhas". Com a queda da produção, tanto na alimentação quanto na venda dos ilhéus, a situação das ilhas tornavase calamitosa.

Neste sentido, como considera Graebin (2004), a família camponesa dos açores era uma associação produtiva, que ligava o trabalho e a vida cotidiana. Portanto, "não ter cereais possuía um significado além do econômico e do simbólico; significava não ter garantias do mínimo para o consumo próprio, nem para o mercado" (GRAEBIN, (2004, p. 88).

Assim, a família dos Açores, considerada por Graebin (2004) uma associação produtiva, ainda tinha outro sistema que, de acordo com Martha Daisson Hameister (2006), colaborou na migração de ilhéus. A autora aborda a questão do sistema de heranças vigente em Portugal durante o Antigo Regime. Neste sistema, apenas o primogênito tinha direito às terras da família, enquanto que os outros filhos sofriam pela falta de herança. De acordo com a historiadora, portanto, migrar, para estes filhos segundos, representava a solução para o problema do acesso a terra.

Segundo Hameisteir (2006), o que a historiografia trata como algo dado, isto é, o problema da superpopulação nas ilhas, na verdade deveria ser revisitado. A autora salienta que a questão demográfica se dava mais pela 
quantia de pessoas que povoavam o mesmo espaço do que propriamente uma superpopulação. O cruzamento de fontes, realizado pela historiadora, demonstrou que muitos daqueles que migraram eram filhos de nobres, desmistificando a ideia de que apenas homens e mulheres pobres se deslocaram no Edital de 1747. Estes filhos se deslocariam para o sul da América Portuguesa já com um estatuto social diferenciado. Corroborando com a autora, Anna Silvia Scott e Gabriel Santos Berutte (2014, p. 112) atestam:

O deslocamento dessa população "excedente" resolvia a situação dos menos aquinhoados, aliviando a situação nas ilhas, ao mesmo tempo em que propiciava o acréscimo do número de povoadores para os territórios americanos. Por outro lado, também representava uma "válvula de escape" para os filhos das famílias melhor posicionadas na hierarquia social, mas que eram preteridos no sistema sucessório em vigor, que privilegiava alguns filhos em detrimento de outros.

Ou seja, para aqueles que sonhavam com uma vida melhor, a situação de migrar poderia representar uma boa opção. Além disso, àqueles filhos segundos das famílias mais abastadas, havia a possibilidade de enriquecer em terras americanas, além de manter - e alargar - o status quo da família, desta vez do outro lado do Atlântico.

Avelino de Freitas Menezes (2014), além de considerar a migração como uma característica fundamental da sociedade portuguesa, ainda atenta para duas formas dela durante o Antigo Regime Português. Ao se basear em estudos de outros historiadores, o autor afirma que haveria o emigrante e o colonizador, sendo que as riquezas já encontradas no Brasil seriam os fatores de cisão entre os dois conceitos. Quanto ao primeiro, o interesse pessoal seria o motor de movimentação, o que resultaria em ganhos para si. Enquanto isso, o colonizador estaria a par de um projeto transcendente a ele próprio. Seria este o caso do povoamento inicial das ilhas do arquipélago, lugar de interesse da coroa para expandir as possessões rumo ao Atlântico. Constituiria, então, aquele migrante, um colonizador. Sendo um, poderia aprimorar práticas relacionadas com a terra e a natureza, desenvolvendo uma relação nas novas propriedades que viria a possuir (MENEZES, 2014).

Como o projeto português dava conta de manter e também expandir a fronteira lusa frente às possessões espanholas, era importante selecionar pessoas que poderiam garantir que ele fosse cumprido. Neste sentido, o Edital de $1747^{6}$ informava não apenas o transporte, mas também as condições que estes súditos migrantes deveriam ter. $\mathrm{O}$ objetivo era povoar as terras com homens e mulheres aptos ao trabalho, a fim de povoar e colonizar a fronteira.

6 O Edital foi transcrito e se encontra disponível em diversas obras. Destacamos o livro organizado por Luiza Iotti, "Imigração e colonização: legislação de 1747 a 1915" (2001) e também o volume 1 dos anais do Arquivo Histórico do Rio Grande do Sul (1977). 
No Edital de 1747, as provisões davam conta do transporte de até quatro mil casais para o meridional brasileiro. Além disso, o Edital abria a possibilidade de imigração de casais estrangeiros ou ainda que casais da ilha da Madeira também migrassem. As condições para que os ilhéus migrassem seria de que os homens não poderiam ter mais de quarenta anos e as mulheres trinta (MENEZES, 2014). Ademais, o Edital fixado em locais de grande circulação de pessoas comunicava diversas garantias aos súditos que migrassem:

[...] as farinhas para a ração, que mando dar no $1^{\circ}$ ano à gente, que se transportar, e este provimento, como também [...] mais, podereis mandar fazer por assento, quando assim vos pareça mais conveniente [...] a cada pessoa de quatorze anos para cima se darão $3 / 4$ de farinha por mês, da medida da terra, um arrátel de peixe ou carne por dia: às pessoas de 14 até 7 completos, a metade desta ração; e as de 7 até 3 anos completos, a $3^{\text {a }}$ parte, e às menores de 3 anos, nada. [...] Para o assento e logradouros públicos em cada lugar, destinará meia légua em quadro, e as demarcações destas porções de terras, se farão por onde melhor mostrar [...]. (PROVISÂO de 9 de agosto de 1747).

O mar também possuía seus desagrados. Visto como selvagem e ameaçador, a longa travessia no oceano Atlântico foi difícil para muitos açorianos. Primeiro, porque as condições do Edital não foram cumpridas pelos responsáveis na viagem. Conforme Graebin (2004), além de os organizadores terem colocado mais pessoas que o permitido, muitos doentes adentraram nos navios. O Governador de Santa Catarina, Manuel Escudeiro, acusava os transportadores de má organização:

No Navio em que a mortandade de gente, e si infecconou de Malignas, e Escorbutos se embarcarão nas Ilhas seiscentas, e oitenta e seis pessoas, alem dos sincoenta homens da sua tripolação; e me persuado a que nehua outra foy a cauza de tanto mal, que vir gente empilhada (ESCUDEIRO apud GRAEBIN, 2004, p. 102).

Ao consultar arquivos disponíveis no Arquivo Histórico Ultramarino, em Portugal, Cleusa Graebin (2004) chegou a números que podem ajudar a compreender as dificuldades da viagem para os ilhéus ${ }^{7}$ : apenas entre 1748 e 1749 , foram registras 109 mortes durante a travessia e 77 em terra, de um total

7 Há de se relativizar as ideias recorrentes da dificuldade enfrentada pelos açorianos, como se o grupo de migrantes fosse o único que passou por complicações durante o período. Acreditase, assim, que não apenas os açorianos sofreram com as ações climáticas, viagem e guerra no processo migratório, mas que era uma condição generalizada no período e no meridional americano. Como os açorianos são o objeto de estudo dessa análise, foca-se neles. 
de 591 transportados. Ou seja, em torno de um terço dos transportados não puderam migrar de fato.

Aqueles que sobreviveram às longas viagens desembarcaram, inicialmente, em Santa Catarina e, após alguns meses, passaram para uma nova viagem rumo a Rio Grande. De acordo com Cleusa Graebin (2004, p. 109):

[...] constata-se que havia a intenção das autoridades de povoar desde o Rio São Francisco até o Cerro de São Miguel, bem como as Missões com casais açorianos. Estes foram se fixando no Rio Grande de São Pedro a partir da Vila de Rio Grande, alcançando os Campos de Viamão (Viamão e Porto Alegre), Santo Amaro, Triunfo e Rio Pardo. Após a invasão do Rio Grande pelos espanhóis, as famílias que estavam vivendo na Vila de Rio Grande se dispersaram para Estreito, Mostardas, Santo Amaro, Triunfo, Porto Alegre, Santo Antonio da Patrulha, Taquari e Osório.

Nesse sentido, a vida em trânsito foi uma constante para os açorianos desde o embarque nas ilhas, ainda na década de 1740, até o estabelecimento nas freguesias, que teria levado em torno de duas décadas (GRAEBIN, 2004). $\mathrm{O}$ trânsito de suas vidas e a necessidade de movimento pelas diferentes regiões do Continente de Rio Grande de São Pedro formam mais um capítulo desse processo migratório marcado pela inconstância.

\section{3 É PRECISO SE MOVIMENTAR: O DESEMBARQUE DOS SÚDITOS MIGRANTES, A DISPOSIÇÃO NO CONTINENTE DO RIO GRANDE DE SÃO PEDRO E A CRIAÇÃO DA FREGUESIA DE SÃO JOSÉ DE TAQUARI}

Após a assinatura do Tratado de Madri, em 1750, na sede da monarquia espanhola, a ideia da Coroa Portuguesa seria de levar os açorianos que desembarcaram em Santa Catarina em 1748 para as Missões. Eles seriam entregues à Coroa Portuguesa em troca da Colônia de Sacramento, cedida para a Espanha (COMISSOLI, 2009). Contudo, a resistência dos indígenas aldeados nas missões e o conflito com os exércitos das Coroas Ibéricas, que desencadeou a Guerra Guaranítica (1754-1756), foi um impeditivo para o deslocamento dos açorianos na região (GRAEBIN, 2004).

Rio Grande, durante a primeira metade do século XVIII, era a única vila do então continente do Rio Grande de São Pedro. Foi o porto desta vila que recebeu os súditos ilhéus a partir de 1750. De acordo com Cleusa Graebin (2004), não é possível estabelecer um número de açorianos que desembarcaram no porto, pois, junto aos casais, desembarcavam, também, seus agregados. $\mathrm{Na}$ época, Rio Grande era uma vila formada por um porto, quatro pequenos quartéis, um armazém, uma ferraria, algumas moradias, uma igreja e ainda o forte Jesus-Maria-José (FORTES, 1978). Este último fora construído ainda em 1737 , quando das pretensões portuguesas de alargar a fronteira com o império 
espanhol e criar um entreposto entre os Campos de Viamão e a Colônia de Sacramento.

Ainda conforme Graebin (2004), a vida dos açorianos, logo após o desembarque em Rio Grande, foi de intensas movimentações e instabilidade. As demandas geradas devido ao Tratado de Madri de 1750, tal como a Guerra Guaranítica e as constantes ameaças dos espanhóis, tomaram conta das preocupações lusitanas, fazendo com que os casais das ilhas ficassem sem o apoio necessário para construir suas casas e gerir as propriedades que lhes seriam concedidas. A demarcação das terras, bem como as promessas de mantimentos e ferramentas, também não puderam ser cumpridas. Tais instabilidades passaram a ser suprimidas apenas duas décadas depois, momento em que as primeiras datas de terras ${ }^{8}$ passaram a ser doadas.

É o caso de Caetano da Silveira, conforme o requerimento ao Provedor da Fazenda Real'. O ilhéu, instalado provisoriamente nos Campos de Viamão, pedia, em 1755, à Provedoria, a isenção do recrutamento da expedição de Gomes Freire de Andrade ${ }^{10}$. Alegava o cabeça do casal, que vivia em extrema pobreza juntamente com sua esposa, filha de casal, e as duas filhas. Caso não fosse possível a liberação, Caetano solicitava, então, que fosse mantida a ração para sua mulher e as filhas, que ficaram totalmente dependentes da colaboração da coroa. A aprovação da provedoria se deu através da liberação do serviço obrigatório ou da manutenção da ração para as filhas. Este caso é capaz de exemplificar a situação calamitosa que estes casais encontravam-se logo após o desembarque em terras do Continente de Rio Grande de São Pedro. Além disso, vale salientar que os casais se utilizavam dos meios públicos para que a situação pudesse ser, de certa forma, resolvida.

As doenças também afetavam a vida de muitos açorianos. Muitos daqueles que não morreram ou enfrentaram episódios de doenças durante a travessia, passaram a desenvolver alguma doença em terras meridionais americanas. Manoel Pinheiro da Silva, também morador dos Campos de

8 De acordo com Helen Osório (2007), havia três possibilidades de se acessar a terra no Continente de Rio Grande de São Pedro durante o período colonial: a doação de sesmarias, normalmente concedidas àqueles responsáveis por feitos militares; a arrematação em praça pública e a doação de datas de terras, concedidas, entre o período de 1750 e 1780 apenas aos casais açorianos migrados a partir do Edital de 1747. Ainda de acordo com a autora, as extensões das datas variavam entre 100 hectares e 300 hectares, sendo que em Taquari, as doações foram todas de 272 hectares.

9 AHRS. Requerimento de 1755 de Caetano de Silveira ao Provedor da Fazenda Real. Maço 06. Documento 01. Todas as informações a respeito do caso de Caetano da Silveira são referentes ao documento referido.

10 A Expedição demarcadora dos Limites foi realizada após o Tratado de Madri (1750), com a necessidade de reconhecimento das terras que seriam da Coroa Portuguesa. Foi liderada pelo Governador do Rio de Janeiro, Gomes Freire de Andrada (GRAEBIN, 2004). 
Viamão, segundo requerimento realizado pelo mesmo, alegava à provedoria que, devido à escassez de alimentos, encontrava-se "gravemente enfermo"; o mesmo solicitava ainda que a provedoria reconhecesse a pobreza que se encontrava e, portanto, o permitiria receber a ração novamente ${ }^{11}$. Neste sentido, conforme Graebin (2004, p. 126):

No cotidiano, na falta de atendimento médico, buscava-se o medicamento no meio natural. Em moléstias de bexiga, usava-se como diurético o chá de barba de milho; para as doenças estomacais, chá de marcela; em casos de dor de cabeça, colocar nas "fontes" folha de laranjeira; para rouquidão, chá de flores de sabugueiro.

O litígio entre os indígenas das Missões e as Coroas Ibéricas fez com que os ilhéus fossem transportados para outras regiões do continente de São Pedro de Rio Grande. Comissoli (2009) considera que, para compreender a distribuição geográfica dos açorianos, é preciso analisar a frustrada tentativa de chegada às Missões. Ainda de acordo com o autor, dois trajetos foram seguidos pelos casais na tentativa de alcançar a região missioneira: a primeira se deu através da expedição demarcadora realizada por Gomes Freire de Andrade, governador do Rio de Janeiro. Nesta expedição, muitos homens açorianos foram obrigados a segui-lo e, com a expulsão dos europeus das Missões, muitos deles acabaram por ficar em Rio Pardo, onde o forte acabara de ser construído ${ }^{12}$.

O segundo caminho reconstruído por Comissoli (2009) foi feito a partir de Rio Grande em direção aos Campos de Viamão. O transporte foi realizado pela Lagoa dos Patos em barcaças. A partir de Viamão muitos casais se dispersaram, formando novos povoados nas margens do Jacuí, dentre eles, Santo Amaro $^{13}$. Explica Comissoli $(2009$, p. 77$)$ que "esta rota explica o porquê de encontrarmos grupos de açorianos ao longo do lago Guaíba e rio Jacuí".

Os casais das ilhas povoaram, então, Santo Amaro, onde já havia um Armazém Real, e Taquari. De acordo com Cristiano Christillino (2004), o conflito entre as Coroas Ibéricas fez com que, pelo lado português, fortificações

11 AHRS. Requerimento de 1764 de Manuel Pinheiro da Silva ao Provedor da Fazenda Real. Maço 06. Documento 02. Todas as informações a respeito do caso de Manuel Pinheiro da Silva são referentes ao referido documento.

12 O forte de Rio Pardo foi construído no ano de 1751, em função da demarcação de terras a partir do Tratado de Madri, realizado em 1750; a freguesia de mesmo nome seria criada apenas uma década após, em 1762. A fundação da freguesia se dá justamente pela fundação da fortaleza (OSÓRIO, 2015).

13 Santo Amaro foi fundado a partir de Rio Pardo: a função central seria de ser um ponto de abastecimentos para as tropas portuguesas que navegavam em direção a Rio Pardo (CHRISTILLINO, 2004). A freguesia de Santo Amaro foi fundada em 1773 enquanto que o Armazém Real já funcionava desde 1752 (OSÓRIO, 2015). Atualmente, Santo Amaro pertence ao município de General Câmara. 
fossem erigidas, justamente com a função de proteger e abastecer as tropas lusas durante os períodos de conflito. Nesse sentido, a povoação de Santo Amaro organizou-se em torno de catorze quilômetros do rio Jacuí e a dezoito do rio Taquari. O número de casais instalados em Santo Amaro foi menor do que em Taquari, devido às doações de sesmarias a chefes militares, como, por exemplo, ao Capitão Francisco Xavier de Azambuja (CHRISTILLINO, 2004).

O desembarque de gentes das ilhas em Taquari se deu antes da década de 1760. A povoação ficava às margens do rio Taquari, este entendido como uma fronteira natural caso os inimigos espanhóis atacassem novamente (GRAEBIN, 2004). Neste contexto, a fundação de Taquari também possuía uma estratégia militar, na medida em que os conflitos com os espanhóis não diminuíam (CHRISTILLINO, 2004).

Pelo Rol de Confessados de Triunfo de $1758^{14}$, é possível perceber que a presença açoriana na região já se dava tempos antes da criação da freguesia (ROSA, 2017). Conforme Helen Osório (2015), a Freguesia de Triunfo foi criada a partir de assentamentos espontâneos e chegava até as margens do rio Taquari. No documento, uma das referências às regiões próximas ao Taquari se dá no item "Do Caí até o Taquari", em que há uma referência aos casais. Nesta lista de casais, constam trinta e três famílias, sendo que algumas delas já possuíam escravos.

A fundação do povoado de Taquari se deu concomitante à construção do Forte no local, pois sua localização permitia o controle da navegação sobre o Taquari. De acordo com Cristiano Christillino (2004, p. 28), “o acesso fluvial deste estava controlado, mas ainda era necessário o domínio sobre as áreas de campo da margem oposta".

Helen Osório (2007) também considera que os rios desempenharam papel fundamental na disposição dos povoados ao longo do Continente de São Pedro. Conforme a autora, "todas essas freguesias encontravam-se às margens dos rios, o que permitia o escoamento de algum excedente agrícola para as redondezas ou mesmo para Porto Alegre" (OSÓRIO, 2007, p. 98).

A fundação da Freguesia de Taquari se deu a partir da instalação dos casais no ano de 1764. Conforme Osório (2015), Taquari foi fundado por parte da iniciativa do governador e também pela necessidade da instalação dos açorianos. Católicos, estes casais trataram de organizar uma capela para que fossem celebrados casamentos e batismos com a proteção divina e também pelo fato de que a religião oficial do Estado Português era o catolicismo.

A paróquia de São José de Taquari foi erigida um ano após a chegada dos casais. Ainda em 1765, foi nomeado o primeiro pároco, Pe. Manoel da

$14 \mathrm{O}$ Rol de Confessados é uma fonte produzida a partir da visita do pároco às casas no período da Páscoa. Tomando a confissão dos fiéis, eram arrolados os moradores dos domicílios, livres ou escravos, acima de sete anos. 
Costa Mata. Arlindo Rubert (1994) acredita que o mesmo seja das ilhas também, justamente pela característica de povoamento da região. Ainda conforme o autor, a Igreja Matriz foi construída na década de 1770, sendo que as bases do prédio permanecem as mesmas até os dias atuais.

\section{CONSIDERAÇÕES FINAIS}

Procurou-se abordar o processo migratório dos açorianos que se deslocaram das ilhas para o Continente de Rio Grande de São Pedro durante meados do século XVIII. Nesse sentido, os condicionantes da migração, sendo elas as crises climáticas, que por sua vez provocavam crise no cultivo do trigo e ocasionaram fome e miséria e o sistema de herança do Antigo Regime Português, são movimentos de relevância para compreender o deslocamento dessas pessoas durante o período referido.

Também se buscou abarcar a disposição dos casais de açorianos no Continente de Rio Grande de São Pedro, tendo como foco final a Freguesia de São José de Taquari, considerando a vida em trânsito dos açorianos, muito debatida na historiografia. A fundação da Freguesia de Taquari se deu, justamente, após a instalação dos primeiros casais de açorianos na região, sendo uma localidade que se originou a partir da presença desse grupo.

A discussão bibliográfica realizada demonstrou que, além de uma bibliografia abrangente sobre o tema, o processo migratório dos açorianos está ligado à necessidade de povoamento da fronteira sul do império português, local de forte conflito com os súditos espanhóis. O uso das fontes demonstrou que a miséria e a insegurança foram companheiras dessas pessoas nos primeiros anos após o desembarque em Rio Grande. As discussões bibliográficas e o uso de variadas fontes resultaram na monografia de trabalho final de curso, desenvolvido no segundo semestre de 2017.

\section{REFERÊNCIAS}

CARVALHO, Vera Regina. Da ilha de açores à freguesia de Taquari: uma trajetória dos imigrantes açorianos no continente de Rio Grande. Revista Estudo \& Debate, v. 9, n. 1, Lajeado, 2002. p. 39-57.

CHRISTILLINO, Cristiano Luís. Estranhos em seu próprio chão: o processo de apropriações de terras na Província de São Pedro do Rio Grande do Sul (O Vale do Taquari no período de 1840-1889). 2004. 374f. Dissertação (Mestrado em História) Universidade do Vale do Rio Sinos. Centro de Ciências Humanas. Programa de Pós Graduação em História. São Leopoldo, 2004.

COMISSOLI, Adriano. Do arquipélago ao continente: estratégias de sobrevivência e ascensão social na inserção açoriana nos Campos de Viamão (séc. XVIII). Revista do Corpo Discente do Programa de Pós-Graduação em História da UFRGS. 2009. p. 7496. 
FORTES, João Borges. Os casais açorianos: presença lusa na formação do Rio Grande do Sul. $2^{\text {a }}$ Ed. Porto Alegre: Martins Livreiro, 1978.

GRAEBIN, Cleusa Maria Gomes. Sonhos, desilusões e formas provisórias de existência: os Açorianos no Rio Grande de São Pedro. 2004. 324 f. Tese (Doutorado em História) - Universidade do Vale do Rio Sinos. Centro de Ciências Humanas. Programa de Pós-Graduação em História. São Leopoldo. 2004.

HAMEISTER, Martha Daisson. Para dar calor à nova povoação: Estudo sobre estratégias sociais e familiares a partir dos registros batismais da Vila de Rio Grande (1738-1763). 2006. 474f. . Tese (Doutorado em História Social) - Universidade Federal do Rio de Janeiro. Programa de Pós Graduação em História Social. Rio de Janeiro. 2006.

MENEZES, Avelino de Freitas. Os açorianos na estruturação do Brasil do Sul: as levas de meados do século XVIII. In.: SCOTT, Ana Silvia Volpi; BERUTE, Gabriel Santos; MATOS, Paulo Teodoro de (org.). Gentes das Ilhas: Trajetórias transatlânticas dos Açores ao Rio Grande de São Pedro entre as décadas de 1740 a 1790. São Leopoldo: Oikos, 2014. p. 60-81.

OSÓRIO, Helen. O império português no sul da América: estancieiros, lavradores e comerciantes. Porto Alegre: Editora da UFRGS, 2007.

OSÓRIO, Helen. A organização territorial em um espaço de fronteira com o império espanhol e seu vocabulário. Notas de Pesquisa. Claves. n.1. Montevidéu, dezembro de 2015. p. 67-90.

PROVISÃO de 9 de agosto de 1747. Dá providências para a condução e o estabelecimento de casais de açorianos no Brasil. In.: IOTTI, Luiza Horn (org.) Imigração e Colonização: Legislação de 1747 a 1915. Porto Alegre: Assembleia Legislativa do Estado do RS. Caxias do Sul: EDUCS, 2001. p. 35-37.

QUEIROZ, Julia Mello. Desenvolvimento econômico, inovação e meio ambiente: a busca por uma convergência no debate. Cadernos do Desenvolvimento, Rio de Janeiro, v. 6, n. 9, jul./dez. 2011, p. 143-170.

RODRIGUES, José Damião. O Comércio dos portos açorianos com o Brasil e a legislação régia (séculos XVII - XVIII). In.: POLANIA, Amelia; MEDINA, Ana Maria Rivera. La gobernanza de los puertos atlanticos, siglos XIV-XX. Madrid: Casa de Velázquez, 2016.

ROL de Confessados da Freguesia de Triunfo de 1758. Arquivo da Cúria Metropolitana de Porto Alegre.

ROSA, Cibele Caroline da. Dos Açores ao Vale do Taquari: aspectos da migração açoriana a partir das relações territoriais e ambientais na longa duração. Monografia (Graduação em História). Lajeado: Universidade do Vale do Taquari, 2017. 
REQUERIMENTO de Caetano de Silveira ao Provedor da Fazenda Real. Maço 06. Documento 01. Arquivo Histórico do Rio Grande do Sul.

REQUERIMENTO de Manuel Pinheiro da Silva ao Provedor da Fazenda Real. AHRGS. Maço 06. Documento 02. Arquivo Histórico do Rio Grande do Sul.

SCOTT, Ana Silvia Volpi; BERUTE, Gabriel Santos. "Gentes das Ilhas": repensando a migração do Arquipélago dos Açores para a capitania do Rio Grande de São Pedro no século XVIII. In.: Scott; Ana Silvia Volpi; BERUTE, Gabriel Santos; MATOS, Paulo Teodoro de (org.). Gentes das Ilhas: Trajetórias transatlânticas dos Açores ao Rio Grande de São Pedro entre as décadas de 1740 a 1790. São Leopoldo: Oikos, 2014. p. 60-81.

SILVA, Cleidirose. Cultura açoriana em Taquari e Paverama: costumes e religiosidade preservados ao longo do tempo. 2009. 150 p. Monografia (Graduação). Curso de História, Centro Universitário Univates: Lajeado, 2009.

TORRES, Luiz Henrique. A colonização açoriana no Rio Grande do Sul (1752-63).

Biblos. V. 16, 2004. P. 177-189.

WIEDERSPAHN, Oscar Henrique. A colonização açoriana no Rio Grande do Sul. Porto Alegre: Escola Superior de Teologia São Lourenço de Brindes/ Instituto Cultural Português, 1979. 